\title{
The Effect of High Switching Frequency on Inverter Against Measurements of kWh-Meter
}

\author{
Isdawimah $^{1}$, Rudy Setiabudy ${ }^{1}$, and Ridwan Gunawan ${ }^{1}$
}

\begin{abstract}
In PV systems connected to the grid requires a $\mathbf{k W h}$ meter to measure the amount of power delivered to the grid, and an inverter to convert the $D C$ voltage generated by $P V$ into $A C$ voltage. The latest generation of Inverter using the high switching frequency to obtain the inverter with good efficiency, small in sizes and lightweight. This led to the emergence of harmonics to the grid through the instrument of $k W h$ meter, and caused the $k W h$-meter is not working properly. This study is intended to obtain the minimum value of the switching frequency which affect the results of measurement of Digital $k$ Wh meters. Kwh-meter tested by varying the switching frequency which is obtained from various types of inverters and from the simulator of switching of high frequencies.
\end{abstract}

Keywords -accuracy of measurement, digital kWh-meter, switching inverter, PV connected to the grid.

\section{INTRODUCTION}

$\mathrm{I}$ nverter one of electronic device which the function is to convert the $\mathrm{DC}$ voltage to $\mathrm{AC}$ voltage which the value of its amplitude and its frequency can be adjusted. The inverter is widely used in power generation system for renewable energy, such as on PV system, wind power, micro hydro and fuel cell. Various configuration of PV-inverter system shown in Figure 1 [1].

In general, the inverter uses a transformer to raise the voltage. Problems that appear to this kind of inverter which is using the transformer are the presence of coreiron losses and copper losses which affect the efficiency of the inverter and ultimately affect the efficiency of the system which is controlled by inverter [2]. Moreover, the usage of transformer caused the dimension of inverter become larger and heavier. One of ways to solve this problem is by using the high frequency up to $200 \mathrm{kHz}$ on switching of inverter process (Figure 2), which is allows the size of transformer and losses of power become smaller [3]-[5]. However, high switching frequency will cause on-load harmonics.

Harmonics are defects on sinusoidal waves due to presence of another wave with frequencies of integer multiples of the fundamental frequency. The level of harmonics that exceed the standard (Table 1 and Table 2) could cause overheating of the equipment, permanent damage to some electronic equipment, reduced the lifetime of equipment and an error of energy measurement [6] - [8]. An example case of error in energy measurement of $15 \%$ occurred in the PV-inverter systems that supply power to the load and the grid [9].

In addition to harmonics, inverters with high switching frequency $(3 \mathrm{kHz}-150 \mathrm{kHz})$ causing electromagnetic distribution [10], where the standard for measuring electromagnetic compability (EMC) and immunity to harmonics in the frequency is not available yet [9].

Given the inverter which available in the market place has reached the switching frequency of $200 \mathrm{kHz}$ while kwh-meter test on PV-inverter system is just reached the inverter's switching frequency of $9 \mathrm{kHz}$ [10]. Therefore, the authors do the test up to $200 \mathrm{kHz}$ by using common

${ }^{1}$ Isdawimah, Rudy Setiabudy, and Ridwan Gunawan are with Departement of Electrical Engineering, Faculty of Engineering, Universitas Indonesia, Depok, Indonesia. E-mail: atadawim@gmail.com; rudy@eng.ui.ac.id; ridwan@eng.ui.ac.id. inverter which available in the market and simulator switching frequency of the inverter for a particular frequency value which is not available in the market. By that way, obtained the correlation between the switching frequencies of the inverter $(0-200 \mathrm{kHz})$ with an error rate of measurement of digital kWh-meter, so it can determine a method to overcome them.

Switching frequency of the inverter is:

$f_{\text {osc }}=\frac{1.1}{R_{T} C_{T}}$

The effective voltage $\left(V_{r m s}\right)$ generated by inverter is :

$V_{r m s}=\frac{1}{2 \pi} \int_{0}^{2 \pi} v(\omega t) d \omega t$

$V_{r m s}=\frac{V_{d c}}{2}$

Total Harmonic Distortion is ratio between effective value of the harmonics against its fundamental effective wave, essentially expressed in \% THD, is equal to:

$T H D_{I}=\frac{\sqrt{\left(I_{2}\right)^{2}+\left(I_{3}\right)^{2}+\left(I_{4}\right)^{2}+\cdots+\left(I_{n}\right)^{2}}}{I_{1}} \times 100 \%$
$T H D_{V}=\frac{\sqrt{\left(V_{2}\right)^{2}+\left(V_{3}\right)^{2}+\left(V_{4}\right)^{2}+\cdots+\left(V_{n}\right)^{2}}}{V_{1}} \times 100 \%$

The thresholds of harmonic of the voltage are classified based on the value of the applied voltage and regulated in IEEE STD 519-1992, as listed in Table 1. For voltages less than $69 \mathrm{kV}$, threshold of harmonic distortion of equipment (Individual Harmonic Distortion) is 3\%, while threshold of overall harmonic distortion (Total harmonic distortion) is 5\%. The threshold for current harmonics are classified based on ratio of the value of the maximum short circuit current with a maximum load current (Table 2).

Harmonics of the inverter output voltage can be obtained by outlining the voltage waveforms using Fourier series. A periodic function $2 \pi \mathrm{f}(\mathrm{x})$ that is integral to the area of $[-\pi, \pi]$, having the numbers $\left(a_{n}\right.$ and $\left.b_{n}\right)$ is referred to as the Fourier coefficients of $\mathrm{f}$, that is [11]:

$a_{n}=\frac{1}{\pi} \int_{-\pi}^{\pi} f(x) \cos n x d x, n \geq 0$

$b_{n}=\frac{1}{\pi} \int_{-\pi}^{\pi} f(x) \sin n x d x, n \geq 1$ 
Configuration with the series formula is :

$\sum f_{n}(x)=\left[a_{0} \cos (0 x)+b_{0} \sin (0 x)\right]+\left[a_{1} \cos (x)+\right.$ $\left.b_{1} \sin (x)\right]+\left[a_{2} \cos (2 x)+b_{2} \sin (2 x)\right]+\left[\mathrm{a}_{3} \cos (3 x)+\right.$ $\left.b_{3} \sin (3 x)\right]+\cdots+\left[\mathrm{a}_{\mathrm{n}} \cos (n x)+b_{n} \sin (3 x)\right]$

From the equation above, we see that at $n=0$ has a value that does not depend on its sinusoidal part, so:

$A_{0}=\frac{1}{\pi} \int_{-\pi}^{\pi} f(x) d x$

$f(x)=A_{0}+\sum_{n=1}^{\infty}\left[a_{n} \cos (n x)+b_{n} \sin (n x)\right]$

Basic components of the output voltage waveform ( $V_{\text {fund }}$ ) inverter is:

$v(\omega t)=\sum_{n=1,3,5 \ldots}^{\infty} \frac{2}{\pi} \frac{V_{d c}}{n} \sin (n \omega t)=0$ untuk $\mathrm{n}=2,4, \ldots$

$V_{\text {fund }}=\frac{\sqrt{2}}{\pi} V_{d c}=0.45 V_{d c}$

Writing the partial sum of the Fourier series $f$ above and expansion it to the infinite value, can be formulated as follows:

$\sum f_{n}(x)=A_{0}+\sum_{n=1}^{\infty} a_{n} \cos (n x)+\sum_{n=1}^{\infty} b_{n} \sin (n x)$

Thus harmonic at $\mathrm{n}$ on the waveform of output voltage $\left(V_{n}\right)$ is:

$V_{n}=\frac{V_{\text {fund }}}{n}$

While the power absorbed by the load is:

$$
\begin{aligned}
& P_{r m s}=\frac{V_{r m s}^{2}}{R} \\
& P_{\text {fund }}=\frac{V_{\text {fund }}^{2}}{R} \\
& \quad v(n)=\frac{v_{n}}{\sqrt{2}}=\frac{2 V_{d c}}{n \pi \sqrt{2}}=\frac{\sqrt{2}}{\pi} \frac{V_{d c}}{n} \text { untuk } n=1,3,5
\end{aligned}
$$

\section{METHOD}

The purpose of testing digital kWh-meter on PVinverter system is to obtain an overview of the influence of inverter's switching frequency $(0-200 \mathrm{kHz})$ against the error rate of measurement on digital $\mathrm{kWh}$-meter.

In this case, the testing was using a single phase digital $\mathrm{kWh}$-meters which available in the market as the Device Under Tested (DUT kWh) with a Constant of 6000 pulses/kWh and a digital $\mathrm{kWh}$-meter class 0.01 as a $\mathrm{kWh}$-meter reference (REF $\mathrm{kWh}$ ).

The testing also used two types of inverters which are available in the market, 6 units inverters with different kind of waveforms and switching frequency, as well as the simulator inverter with adjustable switching frequency $(0-200 \mathrm{kHz})$.

The type of the applied load is a resistive load, such as $100 \mathrm{~W} / 220 \mathrm{~V}$ incandescent lamps. To meet the objectives, then three kinds of kWh-meter testing are applied, there are:

a. Testing the kWh-meter with voltage source from the grid (Figure 3) to measure the level of $\mathrm{kWh}$-meter accuracy.

b. Testing the kWh-meter with PV-inverter system as a voltage source, using inverter which are available in the market with a wide range of switching frequency (Figure 4). The test aims to obtain a correlation between inverter's switching frequency with an error rate of measurement of digital $\mathrm{kWh}$-meter. c. Testing the kWh-meter with voltage source from PVinverters system, using a simulator inverter (Figure 5) with the variation of the switching frequency (0$200 \mathrm{kHz}$ ). This simulator is used to complete the switching frequency value that could not be obtained from the inverter which available in the market. From the test obtained a minimum value of switching frequency in which affect the accuracy of kWhmeters.

The circuit of simulator inverter in Figure 5 consists of a pulse signal (derived from the signal generator) which the waveform, voltage and frequency could be adjusted. This signal is amplified by an amplifier circuit and a step-up voltage transformer. Pulse's signal is then superimposed on sinusoidal waves emanating from the grid, in order to obtain a new waveform resembles the waveform produced by the inverter with certain switching frequency.

\section{RESULT AND DISCUSSION}

In kWh-meter being tested there is LED that flashes with a certain time duration in accordance to the sum of energy measured in units of pulses / $\mathrm{kWh}$. The $\mathrm{kWh}$ meter requires 6000 pulses / $\mathrm{kWh}$ and duration of $100 \mathrm{~ms} /$ pulse. This means the minimum of electrical energy that can be measured by the kwh-meter is 0167Wh.

At first conducted the Testing \#1 (Figure 3) to test the measuring grade of kwh-meter instruments, where kWhmeter is used to measure the power consumption of a resistive load (incandescent bulbs) which are supplied by a single-phase voltage source from the grid. From the test obtained the measurement of $\mathrm{kWh}$-meters by 0.1 kWh (100Wh) within 61.5 minutes.

The results of these measurements indicate that the $\mathrm{kWh}$ meter has been working in accordance to its measuring class (class 0.5).

kWh-meter then tested with second test (Testing \#2 Figure 4), where the kWh-meter is used to measure the power consumption of the resistive load which is supplied by a voltage source from the PV-inverter system. At a given period, the inverter replaced with another inverter from a different switching frequency. Prior to testing, the first stage is measuring switching frequency of each inverter using an oscilloscope. Value of inverter's switching frequency $\left(F_{s}\right)$ is calculated based on the full-wave travel time $(\mathrm{T})$ related to the time scale used (time/div), is equal to:

$F_{S}=\frac{1}{T}$ where $T=n \times$ time $/$ div

$F_{s}=\frac{1}{n \times \text { time } / \text { div }}$

Figure 5 is an example of the measurement results the inverter's switching frequency which are available in the market with the waveform of Quasi-square wave. The time scale (time / div) is $50 \mu$ s with a pulse width (n) 2.6 div, the switching's frequency is:

$F_{s}=\frac{10^{6}}{2.6 \times 50}=7.7 \mathrm{kHz}$

This test is using 6 units of single-phase inverter in various waveforms and switching frequency (Table 3), where the value of switching frequency of inverters which are available in the market is in the order of $\mathrm{kHz}$, 
the range of $(6.7 \mathrm{kHz}-117 \mathrm{kHz})$. This becomes a constraint in testing the $\mathrm{kWh}$-meter for low value of switching frequency (in the order of $\mathrm{Hz}$ ).

Within the same value of the voltage, current and power factor, result of the Testing \#2 compared to the Testing \#1 (Table 4), in order to obtain the time difference $(\mathrm{dt})$ and the energy difference $(\mathrm{dWh})$. Data of measurement in Table 4 shown that in the Testing \#2, kWh-meter measuring greater energy compared to Testing \#1 and the longer the greater their energy difference. Difference in measurement caused by the presence of harmonics generated by the inverter (Table 3 ) exceeds the threshold (Table 1 and Table 2).

The Test \#3 is testing kWh-meter with voltage source from PV-inverter systems. Inverters which are used in the form of simulator with adjustable switching frequency.

Figure 6 is an example of the process of formation of a new wave on the simulator-inverters, where a pulse signal with $277 \mathrm{~Hz}$ switching frequency are superimposed on a sinusoidal wave with a frequency of $50 \mathrm{~Hz}$, resulting in a multilevel waveform with the switching frequency is $277 \mathrm{~Hz}$.

By adjusting the frequency of the pulse signal from the signal generator, will obtained the waves within various switching frequency. In addition to a low switching frequency $(\mathrm{Fs}<1000 \mathrm{~Hz}$ ), this simulator can generate a high switching frequency, as shown in Figure 7.

The measurement results of Testing \#3 in the form of a graph illustrating the relationship between the switching frequency and the measurement error (Figure 8). The testing is executed till the switching frequency reached at $200 \mathrm{kHz}$ and produced a significant measurement error $(7.7 \%-17.2 \%)$, exceed the class of measuring instrument itself.

If the results of Testing \#3 compared to the results of Testing \#1 (Table 5), then it obtain the same conditions with the Testing \#2, where the kWh-meter on Testing \#3 measuring greater energy compared to $\mathrm{kWh}$-meter in the Testing \#1. This is caused by the presence of the THD on the inverter (Table 6).

\section{CONCLUSION}

This study aims to get an optimum performance of $\mathrm{kWh}$-meter when used to measure the electrical energy supplied by the PV-inverter system.

The method used was testing the kWh-meter with various voltage sources derived from the grid, the inverter from the PV system and from PV-inverter system but the inverter in the form of simulator. This simulator is used to expand the inverter's switching frequency becomes $(71 \mathrm{~Hz}-200 \mathrm{kHz})$ in order to overcome the limitation of switching frequencies which are available in the market.
From the testing results obtained the minimum switching frequency that affecting measurement errors digital kWh-meter, that is as big as $556 \mathrm{~Hz}$. Measurement error is decreased when the switching frequency is enlarged.

So it can be stated that the higher the inverter's switching frequency, the measurement errors are getting smaller. The measurement error is in a significant value $(7.7 \%-17.2 \%)$, exceed the class of measuring instrument itself, even the switching frequency is enlarged to $200 \mathrm{kHz}$. This is due to the harmonic distortion exceeds the allowable standard.

\section{ACKNOWLEDGEMENT}

Gratitude to such kind of programs which are supported by Decentralization Research "Skim Hibah Bersaing" in which is allocation for Polytechnic State of Jakarta under contract number: 6/PL3.B/SPK/2013, that makes this research could be realized and released.

\section{REFERENCES}

[1]. Zheng Zhao et al, "Derivation, Analysis, and Implementation of a Boost-Buck Converter-Based High-Efficiency PV Inverter,' IEEE Transactions on Power Electronics, vol. 27, no. 3 March 2012.

[2]. Savita Nema, R. K. Nema, and Gayatri Agnihotri,"Inverter topologies and control structure applications: A review," Journal of Renewable and Sustainable Energy vol.3, 2011.

[3]. Bernard J. Szymanski, et al.," Operation of Photovoltaic Power Systems with Energy Storage," IEEE trans., pp. 86-91, 2011

[4]. Li ZHU, Keliang ZHOU, Wenjie ZHU and Xiu'e SU,'High Frequency Link Single-Phase Grid-Connected PV Inverter,' presented at the IEEE International Symposium on Power Electronics for distributed Generation Systems, pp.133-137, 2010.

[5]. Ned. Mohan, T.M Undeland and W.P. Robbins, "Power Electronics, Converter - Applications and Design,"John Wiley and Son,Inc, 2008, pp. 8-1;9-1.

[6]. Prof. Ahmed A. Hossam-Eldin Reda, Mohammed Hasan,"Study of the Effect of Harmonics on Measurements of the Energy Meters," presented at the The Eleventh International Middle East Power System Conf. (MEPCON'2oo6), pp. 547-550, 2006.

[7]. A. Domijan, Jr., E. Embriz-Santander, A. Gilani,"Watthour Meter Accuracy Under Controlled Unbalanced Harmonic Voltage and Current Conditions," IEEE Trans. on Power Delivery, Vol. 11, No. 1, pp. 64-72, January 1996.

[8]. L. Siqueira A.M. Carneiro, Filho M.De Oliveira, $\mathrm{PhD}$,"Assessment of Harmonic Distortions on Power and Energy Measurements," IEEE trans., pp. 105-109, 2000.

[9]. J. Kirchhof, G. Klein, "Result of the optinus project-deficits and Uncertainties in Photovoltaic Inverter Test Procedures," 2 presented at the 4th European Photovoltaic Solar Energy Conf. and Exhibition, pp. 1-4, 21-25 September 2009

[10]. Dipl.-Ing. Elmar Stachorra, Dipl.-Ing.Willi Horenkamp, Dipl.Ing. Timo Wild," The Influence of Conducted PQ-Phenomena on the Measurement Accuracy of Smart Meters," presented at the C I R E D 21st International Conf. on Electricity Distribution Frankfurt, pp. 1-4, 6-9 June 2011.

[11]. Kreyszig,E., "Advanced Engineering Mathematics," Singapore: John Wiley \& Sons, 2006, pp. 477-529.

[12]. IEEE SM 519-1992,"IEEE Recommended Practices and Requirements for Harmonic Control in Electrical Power Systems," American National Standard (ANSI),pp. 79, April 12, 1993 

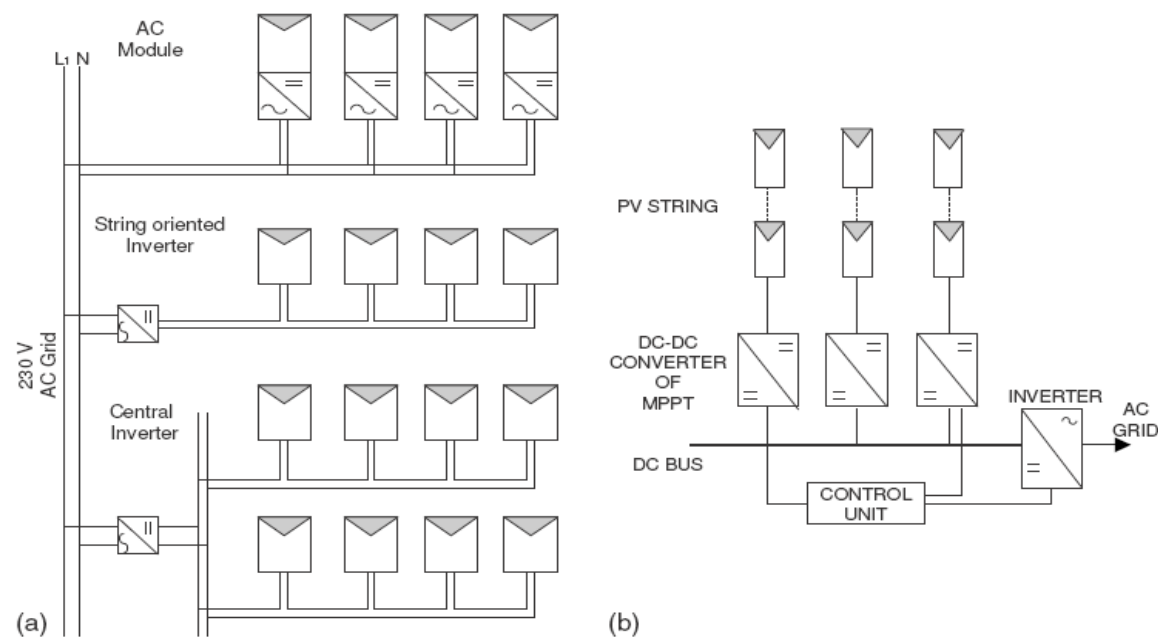

Figure 1. Configuration of PV-inverter [1]

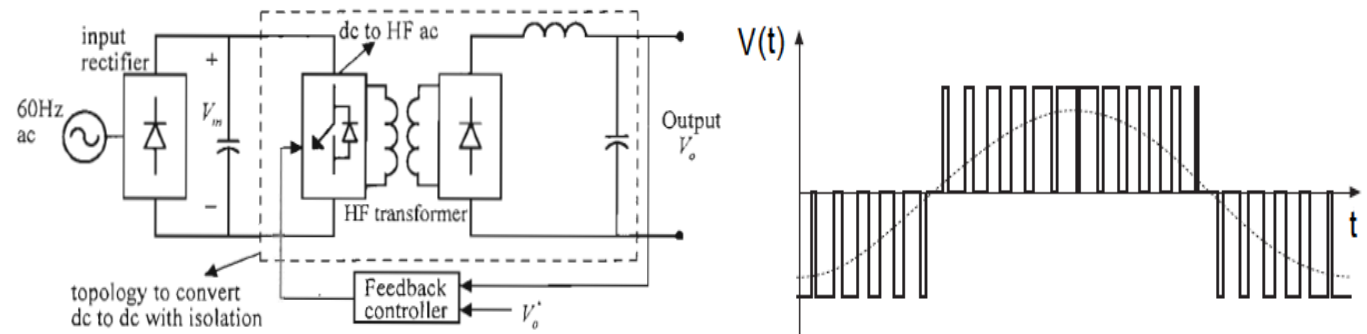

Figure 2. Inverter using the HF transformer (left) and HF signal modulation (right) [5]

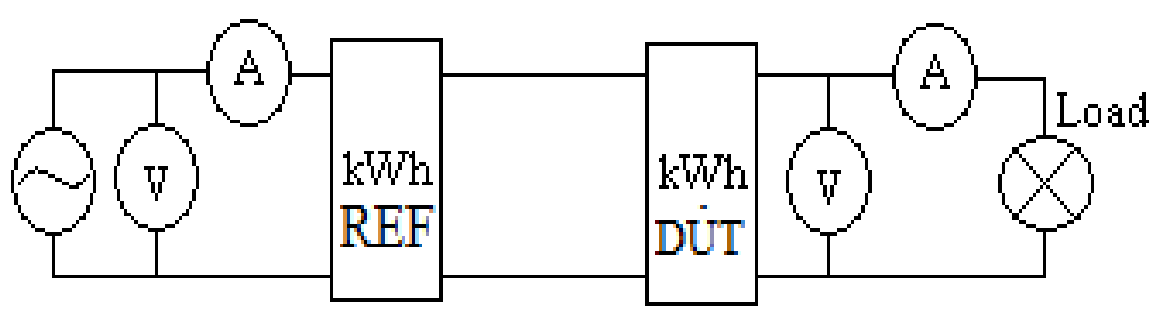

Figure 3. Testing the kWh-meter with voltage source from the grid

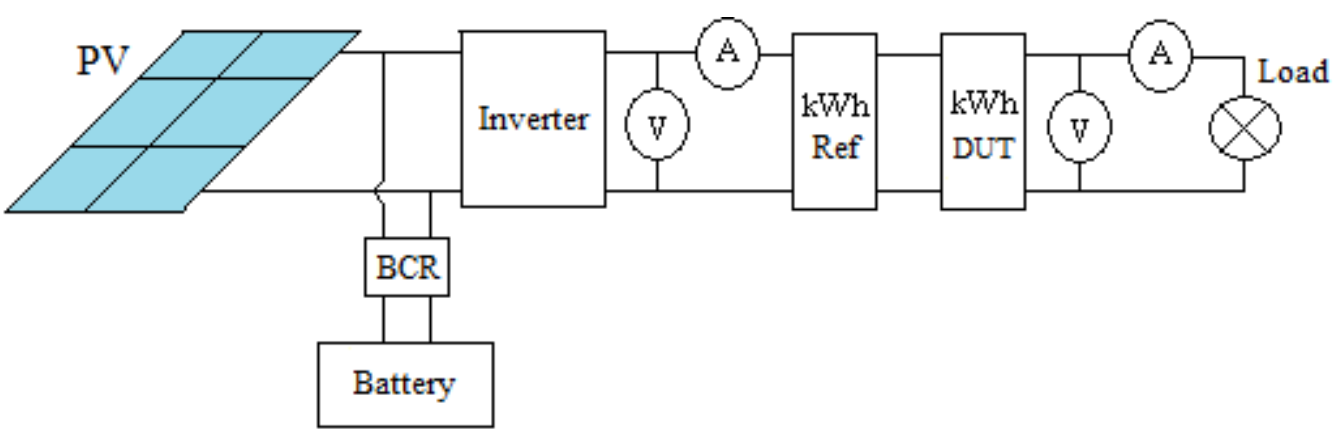

Figure 4. Testing the kWh-meter with PV-inverter system as a voltage source
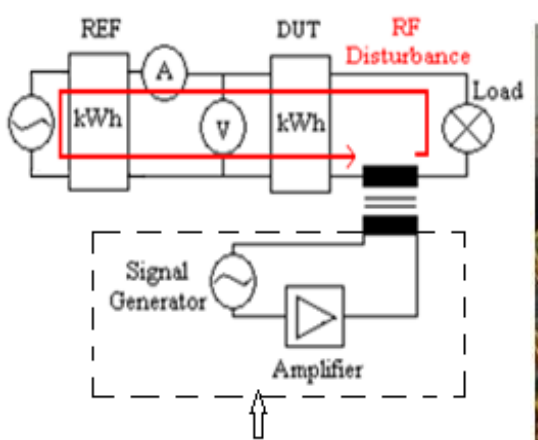

Switching Frequency Simulator

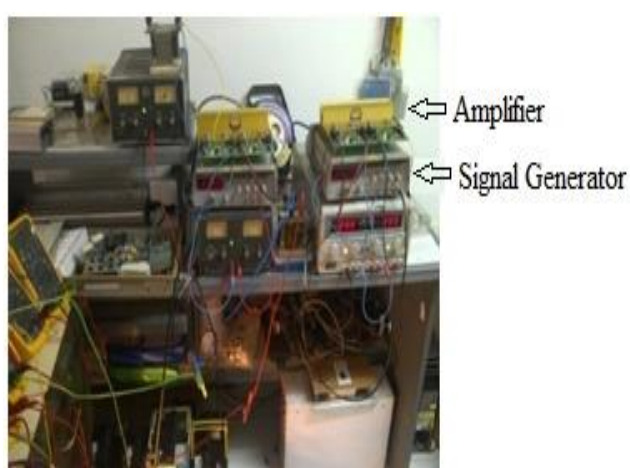

Figure 5. Testing the $\mathrm{kWh}$-meter with voltage source from PV-inverters system, using a simulator inverter 


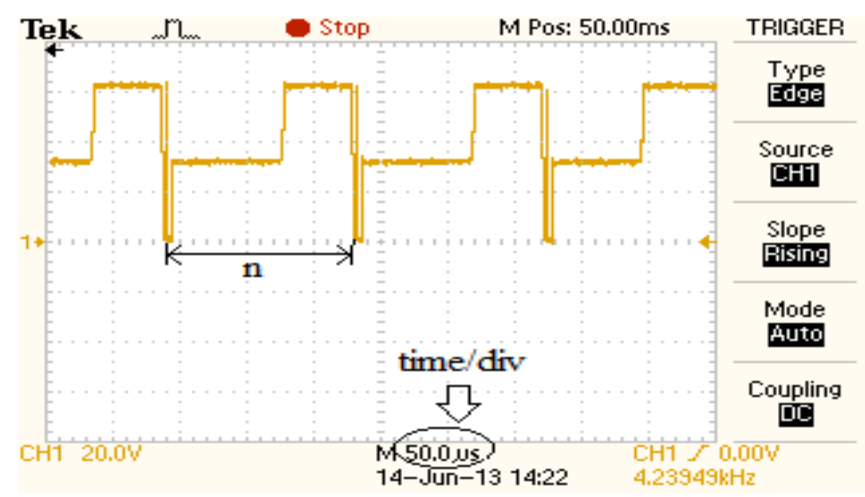

Figure 6. Switching frequency of inverter

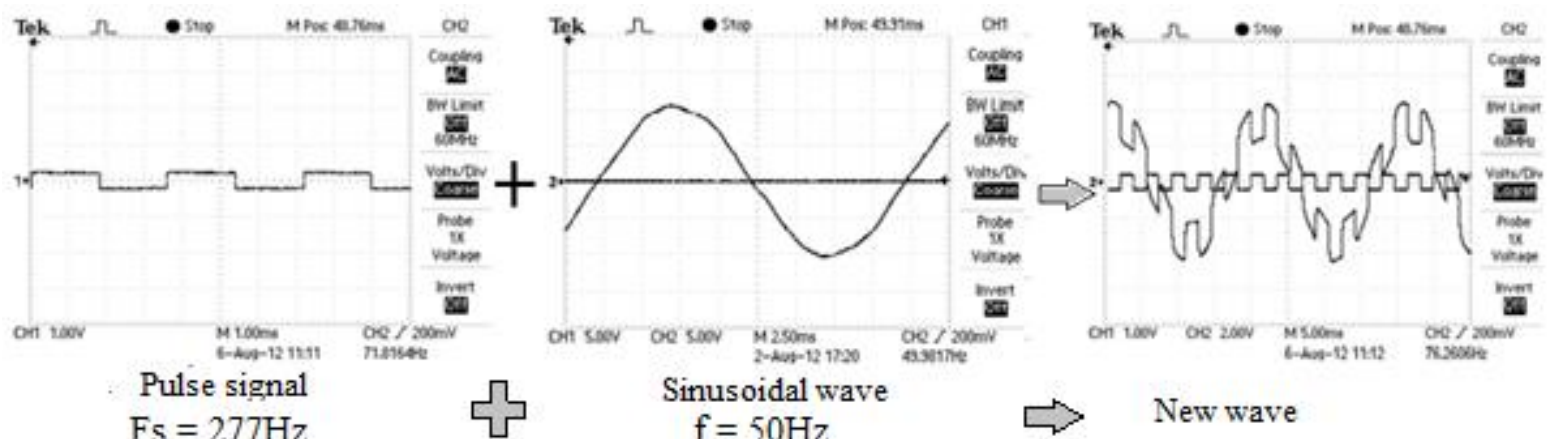

$\mathrm{Fs}=277 \mathrm{~Hz}$

Figure 6. Process of forming a new wave in the simulator-inverter
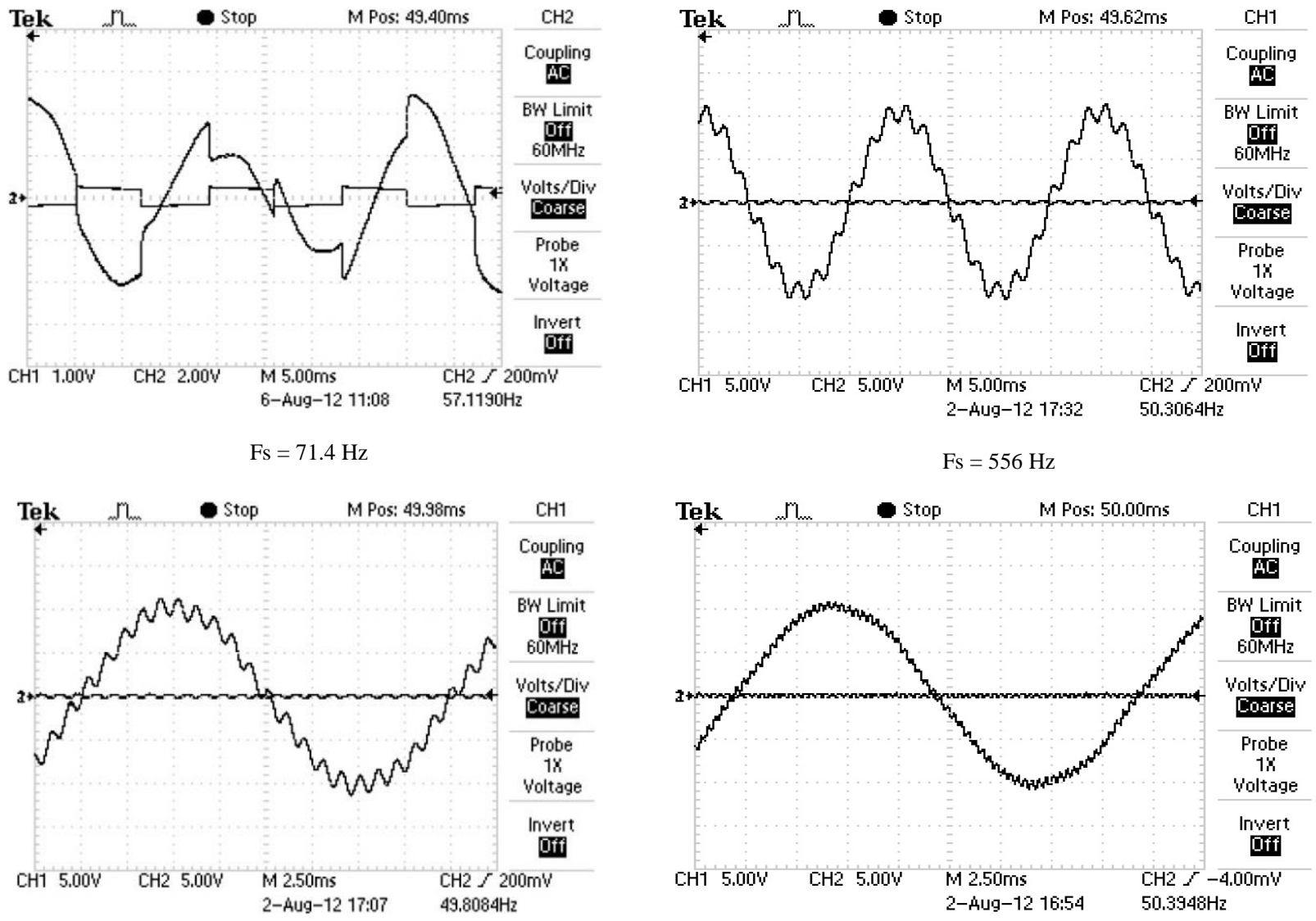

$\mathrm{Fs}=1015 \mathrm{~Hz}$

$\mathrm{Fs}=97.56 \mathrm{kHz}$

Figure 7. Various of switching frequencies generated by the simulator-inverter 


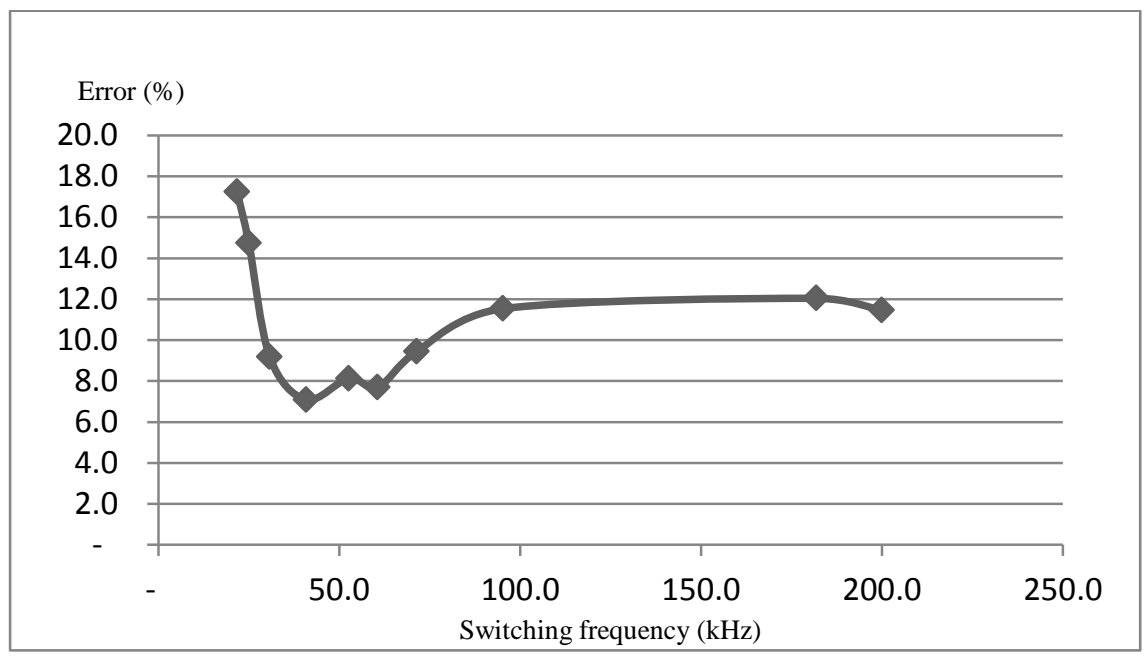

Figure 8. Graph of error energy meter measurement depend switching frequency inverter

TABLE 1.

VOLTAGE DISTORTION LIMITS

\begin{tabular}{lcc}
\hline \hline Bus Voltage at PCC & $\begin{array}{c}\text { Individual Voltage } \\
\text { Distortion }(\%)\end{array}$ & $\begin{array}{c}\text { Total Voltage } \\
\text { Distortion THD }(\%)\end{array}$ \\
\hline $69 \mathrm{kV}$ and below & 3.0 & 5.0 \\
$69.001 \mathrm{kV}$ through $161 \mathrm{kV}$ & 1.5 & 2.5 \\
$161.001 \mathrm{kV}$ and above & 1.0 & 1.5
\end{tabular}

NOTE: High-voltage systems can have up to $2.0 \%$ THD where the cause is an HVDC

Terminal that will atteanuate by the time it is tapped for a user.

Source: IEEE STD 519-1992

TABLE 2.

CURRENT DISTORTION LIMITS FOR GENERAL DISTRIBUTION SYSTEMS (120 V THROUGH 69,000 V)

\begin{tabular}{|c|c|c|c|c|c|c|}
\hline \multicolumn{7}{|c|}{$\begin{array}{c}\text { Maximum Harmonic Current Distortion in Percent of } \mathrm{I}_{\mathrm{L}} \\
\text { Individual Harmonic Order (Odd Harmonics) }\end{array}$} \\
\hline $\mathrm{I}_{\mathrm{sc}} / \mathrm{I}_{\mathrm{L}}$ & $<11$ & $11 \leq \mathrm{h}<17$ & $17 \leq h<23$ & $23 \leq h<35$ & $35 \leq \mathrm{h}$ & TDD \\
\hline$<20^{*}$ & 4.0 & 2.0 & 1.5 & 0.6 & $0 . \overline{3}$ & 5.0 \\
\hline $20<50$ & 7.0 & 3.5 & 2.5 & 1.0 & 0.5 & 8.0 \\
\hline $50<100$ & 10.0 & 4.5 & 4.0 & 1.5 & 0.7 & 12.0 \\
\hline $100<1000$ & 12.0 & 5.5 & 5.0 & 2.0 & 1.0 & 15.0 \\
\hline$>1000$ & 15.0 & 7.0 & 6.0 & 2.5 & 1.4 & 20.0 \\
\hline \multicolumn{7}{|c|}{$\begin{array}{l}\text { Even harmonics are limited to } 25 \% \text { of the odd harmonic limits above } \\
\text { distortion that result in a dc offset, e.g., half-wave converters, are not allowed. } \\
\text { power generation equipment is limited to these values of current disttortion. } \\
\text { Regardless of actual } \mathrm{I}_{\mathrm{sc}} / \mathrm{I}_{\mathrm{L}}\end{array}$} \\
\hline \multicolumn{7}{|c|}{$\begin{array}{l}\text { Where } \\
\text { a short circ } \\
\text { ent (fundar }\end{array}$} \\
\hline
\end{tabular}

Source: IEEE STD 519-1992

TABLE 3.

SWITCHING FREQUENCY (FS) AND THD INVERTER

\begin{tabular}{lccc}
\hline \hline \multicolumn{1}{c}{ Wave Shape } & $F_{s}(\mathrm{kHz})$ & THD-V $(\%)$ & THD-I $(\%)$ \\
\hline Sine wave & 117 & 27,8 & 40,1 \\
Quasi-square wave & 50 & 22,3 & 23,5 \\
Multilevel & 40 & 2,4 & 19,6 \\
Quasi-square wave & 7,7 & 2,7 & 18,4 \\
Quasi-square wave & 7,1 & 2,0 & 20,0 \\
Square wave & 6,7 & 2,7 & 12,7 \\
\hline \hline
\end{tabular}

TABLE 4.

COMPARISON OF ENERGY MEASUREMENT FROM GRID (TESTING \#1) AND PV-INVERTER (TESTING \#2)

\begin{tabular}{cccccccc}
\hline \hline & Load & & Grid & Inverter & Wh1-Wh2 & \multicolumn{3}{c}{$\mathrm{t} 1-\mathrm{t} 2$} \\
$\mathrm{~d}(\mathrm{~V})$ & $\mathrm{I}(\mathrm{A})$ & $\mathrm{pf}$ & $\mathrm{Wh} 1$ & $\mathrm{Wh} 2$ & $\mathrm{dWh}$ & $\mathrm{dWh}(\%)$ & -1.2 \\
\hline 220 & 0,44 & 1 & 100.1 & 97.9 & -2.2 & -2.2 & 8.2 \\
220 & 0,44 & 1 & 200.1 & 216.0 & 16.0 & 8.0 & 9.2 \\
220 & 0,44 & 1 & 300.0 & 330.2 & 30.2 & 10.1 & 17.4 \\
\hline \hline
\end{tabular}


TABLE 5.

COMPARISON OF ENERGY MEASUREMENT FROM GRID (TESTING \#1) AND SIMULATOR (TESTING \#3)

\begin{tabular}{cccccccc}
\hline \hline & Load & & Grid & Inverter & Wh1-Wh2 & \multicolumn{3}{c}{ t1-t2 } \\
$\mathrm{V}(\mathrm{V})$ & $\mathrm{I}(\mathrm{A})$ & $\mathrm{pf}$ & Wh1 & Wh2 & $\mathrm{dWh}$ & $\mathrm{dWh}(\%)$ & -0.2 \\
\hline 220 & 0,44 & 1 & 100.1 & 99.5 & -0.6 & -0.6 & 9.0 \\
220 & 0,44 & 1 & 200.1 & 216.0 & 16.0 & 8.0 & 9.2 \\
220 & 0,44 & 1 & 300.0 & 330.2 & 30.2 & 10.1 & 17.4 \\
\hline \hline
\end{tabular}

TABLE 6 .

THD ON VARIOUS INVERTER

\begin{tabular}{cccc}
\hline \hline Type of inverter & Switching frequency $(\mathrm{kHz})$ & THD-V (\%) & THD-I (\%) \\
\hline Simulator inverter & 0,46 & 22,3 & 19,6 \\
Simulator inverter & 0,83 & 2,7 & 18,4 \\
Simulator inverter & 3,05 & 2,0 & 20,0 \\
Simulator inverter & 83,3 & 2,7 & 12,7 \\
\hline \hline
\end{tabular}

